\title{
DESPITE DRAMATIC LOCAL CHANGES, THE METACOMMUNITY STRUCTURE OF A SEMIARID SCRUB REMAINS UNAFFECTED AFTER 23 YEARS
}

\section{DRAMÁTICOS CAMBIOS EN COMUNIDADES VEGETALES LOCALES NO AFECTARON A LA ESTRUCTURA DE UNA METACOMUNIDAD SEMIÁRIDA DESPUÉS DE 23 AÑOS}

\author{
Monserrat Jiménez $Z^{1-2}$, , J. Alejandro Zavala-Hurtado ${ }^{1 *}$, Carlos Martorell $\stackrel{3}{ }$, ERnesto Vega ${ }^{4}$, \\ Esther Sandoval-Palacios ${ }^{5}$, ๑Gilberto Hernández-Cárdenas ${ }^{1}$, Beatriz Rendón-Agullar ${ }^{1}$
}

\begin{abstract}
${ }^{1}$ Departamento de Biología, Universidad Autónoma Metropolitana-Iztapalapa, México.
${ }^{2}$ Doctorado en Ciencias Biológicas y de la Salud, Universidad Autónoma Metropolitana-Iztapalapa, México.

${ }^{3}$ Departamento de Ecología y Recursos Naturales. Facultad de Ciencias, Universidad Nacional Autónoma de México, México. ${ }^{4}$ Instituto de Investigaciones en Ecosistemas y Sustentabilidad. Universidad Nacional Autónoma de México, México.

${ }^{5}$ Comisión de Recursos Naturales y Desarrollo Rural. Secretaría del Medioambiente, México.
\end{abstract}

*Corresponding author: jazh@xanum.uam.mx

\begin{abstract}
Background: Understanding changes in local community composition along environmental gradients is essential for studying the long-term metacommunity dynamics. The metacommunity structure depends on the distribution of species along environmental gradients in terms of their coherence (continuity in their distribution range), species turnover and grouping of their range limits. A Clementsian structure would be defined by coherent ranges, significant turnover and sharp limits between local communities. All other things equal, a Gleasonian structure is distinguished by the absence of clear boundaries between local communities.

Questions: The structure of a scrubland/semiarid/xeric metacommunity changes 23 years after its first characterization? Do environment and spatial variables determine the metacommunity structure?

Species studied: 104 perennial-plant species.

Study site and dates: Zapotitlán semi-arid valley, Puebla, in 1980 and 2003.

Methods: Metacommunity structure and its relationship to environmental (edaphic) and spatial (altitude, slope and geographical location) variables were analyzed using data from the two historic surveys.

Results: In 1980 a Clementsian structure was determined, which remained unchanged after 23 years. The importance of environmental filters decreased from 1980 to 2003.

Conclusions: The prediction that, due to stochastic dispersion of propagules, the metacommunity would tend toward a Gleasonian structure was not fulfilled. There was no evidence for homogenization, although local tetechera communities (with dominance of the giant columnar cactus Cephalocereus tetetzo) had been invaded and transformed into shrubland communities. Local communities and the metacommunity should be monitored continuously to understand of the long-term structuration of these systems.
\end{abstract}

Keywords: Clementsian structure, environmental gradient, metacommunity structure, shrubland encroachment, variance partition.

\section{Resumen}

Antecedentes: Comprender los cambios en la composición de comunidades locales a lo largo de gradientes ambientales es esencial para estudiar la dinámica metacomunitaria a largo plazo. La estructura metacomunitaria depende de la distribución de especies en gradientes ambientales por su coherencia (continuidad del rango de distribución), recambio de especies y agrupación de límites de distribución. Una estructura Clementsiana presenta rangos coherentes, recambio significativo y límites claros entre comunidades locales. Una estructura Gleasoniana se distingue por la ausencia de límites claros entre comunidades locales.

Preguntas: ¿La estructura de una metacomunidad de matorral xerófilo cambió 23 años después de su primera caracterización?; ¿Las variables ambientales y espaciales determinan la estructura de la metacomunidad?

Especies de estudio: 104 especies de plantas perennes.

Sitio y años de estudio: Valle semiárido de Zapotitlán, Puebla, en 1980 y 2003.

Métodos: La estructura de la metacomunidad y su relación con variables ambientales (edáficas) y espaciales (altitud, pendiente y ubicación geográfica) se analizaron utilizando datos de los dos estudios históricos.

Resultados: En 1980 se reconoció una estructura Clementsiana, que no cambió después de 23 años. La importancia de filtros ambientales disminuyó en ese período.

Conclusiones: No se cumplió la predicción de que la dispersión estocástica de propágulos conduciría hacía una estructura Gleasoniana. No hubo evidencia de homogeneización de la vegetación, aunque las comunidades de tetechera (domina el cactus columnar gigante Cephalocereus tetetzo) habían sido invadidas y transformadas en matorral. La dinámica de la metacomunidad debe ser monitoreada continuamente para comprender la estructuración a largo plazo de estos sistemas.

Palabras clave: estructura Clementsiana, estructura de la metacomunidad, gradiente medioambiental, invasión de matorral, partición de varianza.

This is an open access article distributed under the terms of the Creative Commons Attribution License CCBY-NC (4.0) international.

https://creativecommons.org/licenses/by-nc/4.0/ 
Although patterns in ecological communities change over spatio-temporal scales, ecological theory has mostly focused on a single scale, assuming that communities are closed and stable entities over time (Leibold et al. 2004). However, ecologists are increasingly focusing on metacommunities. In this approach, communities are considered as open entities that maintain different levels of functional interconnection in a regional environment (Holyoak et al. 2005). Thus, metacommunities are defined as "... a set of local communities that are connected by dispersal of multiple species that can potentially interact" (Wilson 1992). The meta-community level allows us to incorporate large space-time scales to community ecology. For example, the meta-community approach can range from microarthropod communities in lichen patches (small scale), to studies across biogeographic provinces or continents (large scale) (Mouquet \& Loreau 2003, Chase \& Bengtsson 2010). On the other hand, metacommunity dynamics is apparently closely related to environmental filters (abiotic interactions), biotic interactions and to the dispersal of species between local communities (Holyoak et al. 2005, Puth \& Post 2005, Hutchinson 2008, Logue et al. 2011). These factors change in space and time (Devlaeminck et al. 2005, Leibold \& McPeek 2006). Therefore, it is important to consider the environmental heterogeneity between patches and the relatively unfavorable matrix in which to advance knowledge, conservation and management of ecosystems (Leibold et al. 2004, Datry et al. 2015).

Based on metacommunities theory, attempt have been made to analyze the elements of metacommunity structure (EMS) (Leibold \& Mikkelson 2002) as an exploratory examination of possible changes in metacommunity structure (Keith et al. 2011). EMS are used to characterize the emergent properties of metacommunities using an incidence matrix with three measures: (1) coherence, or the degree of continuity of species across a major gradient; (2) turnover, or species replacement from site to site; and (3) boundary clumping, the extent to which the limits of the ranges of different species are clustered together (Leibold \& Mikkelson 2002, Presley et al. 2010). Based on this approach, ecologists have described theoretical patterns for the distribution of species between patches in a metacommunity (Leibold \& Mikkelson 2002) (Figure 1). These are: a) Nested subsets (positive coherence and negative turnover). There are fewer embedded absences and less species turnover than those expected by chance. Communities with few species form nested subsets of increasingly speciose communities, due to the tolerance of each species to abiotic conditions (Patterson \& Atmar 1986). b) Checkerboards (negative coherence). There are significantly more embedded absences than expected by chance. Strong competition may result in this pattern due to species pairs with mutually exclusive distributions
(Diamond 1975). c) Clementsian (positive coherence, positive turnover, and positive clumping). Discrete communities replace each other along gradients and share few species with other types of communities; coexistence depends on interaction with other species (Clements 1916). d) Gleasonian (positive coherence, positive turnover, and non-significant clumping). This pattern differs from the Clementsian, in that the grouping of boundaries is not different from chance. Species are distributed along environmental gradients independently of other species and coexistence results from casual similarities in requirements or tolerances (Gleason 1926). e) Evenly spaced gradients (positive coherence, positive turnover, and negative clumping). There is significantly a lower grouping of species' range limits than expected by chance. This model was proposed by Tilman in 1982, the assumption is that there is strong competition between species, so the species ranges are evenly arranged along gradients with no discrete communities. f) Random (all EMS are indistinguishable from a random expectation). In this model there is no pattern in species distributions (Simberloff 1983).

Additional six quasi-structures have been proposed (Presley et al. 2010) (Figure 1): g) quasi-nested clumped species loss, h) quasi-nested stochastic species loss, i) quasi-nested hyperdispersed species loss, j) quasiClementsian, k) quasi-Gleasonian, and 1) quasi-evenly spaced. These quasi-structures have the same characteristics as their associated basic structures, except that turnover does not differ significantly from a random expectation. For example, a nested metacommunity may exhibit loss of hyperdispersed species, with stochastic distribution or grouped between sites (Presley et al. 2010).

The EMS is based on an analysis of the distribution patterns of species along a major compositional-variation axis assumed to correspond to an important environmental or geographical gradient (Leibold \& Mikkelson 2002, Leibold et al. 2004). An explicit consideration of environmental gradients and of the dispersal ability of different species between local communities would allow unraveling the role of stochastic and/or deterministic factors in structuring the metacommunity (Ozinga et al. 2004, Meynard et al. 2013, Denelle et al. 2019). A few previous studies have evaluated changes in the structure of metacommunities over time. Ellis et al. (2006) analyzed the structural changes in space and time (from 1978 to 2003) of the mosquito communities that inhabit water-filled holes in trees in southeastern Florida, USA, finding that temporal variation was greater than the spatial one. Keith et al. (2011) found in Dorset, England, that the structure of the plant metacommunity was Clementsian and that, despite the recorded loss of species, the metacommunity remained unchanged over 70 years. 


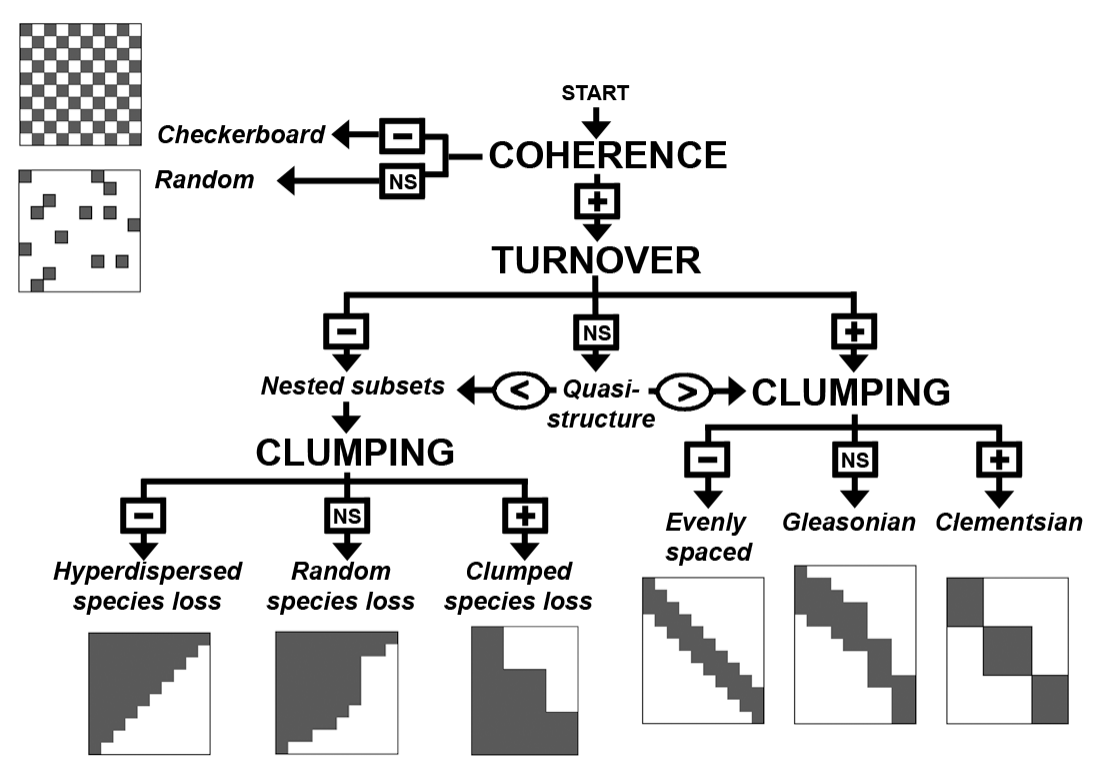

Figure 1. Graphical representation of the possible combinations of EMS to differentiate between the six idealized structures (Leibold \& Mikkelson 2002) and the associated quasi-structures (Presley et al. 2010). Modified from Presley et al. (2010).

There are few long-term studies that quantify changes in plant metacommunity structure in intertropical drylands (Miller et al. 2012, Stewart et al. 2014, Abella et al. 2019). These environments are important due to their high diversity and endemism of plant species. Approximately $60 \%$ of the plants that grow in the semiarid areas of Mexico are endemic (Rzedowski 1978). In addition, arid and semi-arid plant communities are characterized by patchy spatial arrangements allowing for a straightforward metacommunity analysis (Wilson 1992, Aguiar \& Sala 1994, Holyoak et al. 2005). In this arrangement, the spatial colonization between patches can be affected by geographical distance, interspecific dispersal differences, and environmental filters. These factors may be determinants of the structure, dynamics (MacArthur \& Wilson 1967, Nathan \& Muller-Landau 2000, Pueyo et al. 2008) and persistence of local communities (Holyoak et al. 2005, Hubbell 2005, Venable et al. 2008, Jones et al. 2015).

Zavala-Hurtado (1982) and Sandoval-Palacios (2010) analyzed the changes in composition and abundance of perennial plant species in 26 patches from three vegetation types (Table 1) over a 23-year period (1980-2003) in the semi-arid Zapotitlán valley, Mexico. Sites classified in 1980 as cardonal and shrubland did not show significant changes in their composition of species in 2003. However, $62.5 \%$ (10 out of 16) sites occupied by tetechera changed to shrubland, suggesting that tetechera is unstable through time (Sandoval-Palacios 2010). These changes appeared to involve an "invasion" of one community by another and a trend towards a homogenization of the metacommunity
(Sandoval-Palacios 2010). This led us to ask whether these changes have an effect on the structure of the spatial distribution of the species in the metacommunity, and how much does the environment and geographical distance influence the structure of the metacommunity.

Using the species' presence-absence data from ZavalaHurtado (1982) and Sandoval-Palacios (2010), we analyzed the structure of the metacommunity in the Zapotitlán valley. We expected the turnover and agglomeration of range limits would have decreased due to homogenization, resulting in a change from a Clementsian or quasi-Clementsian in 1980 toward a Gleasonian or quasi-Gleasonian structure in 2003. In addition, we expected to find changes in the effect of environmental (edaphic) and spatial (latitude, slope and geographical distance) gradients on the metacommunity structure. Thus, we expected that environmental and spatial variables at the local community level would explain, at least partially, the structure of the metacommunity. If the structure of the metacommunity in 2003 implied greater independence between the distribution ranges of the species, we would expect environmental filters to be of lesser importance that year.

\section{Materials and methods}

Study site. The study area is located in the semi-arid Zapotitlán valley in central Mexico (Figure 2), an intertropical local basin that covers an area of $413.89 \mathrm{~km}^{2}$ (located in $18^{\circ} 11^{\prime}-18^{\circ} 25^{\prime} \mathrm{N}$ and $97^{\circ} 39^{\prime}-97^{\circ} 22^{\prime} \mathrm{W}$ ) in the Tehuacan-Cuicatlan Biosphere Reserve (Zavala-Hurtado 
Table 1. Three vegetation types recognized by Zavala-Hurtado (1982) and Sandoval-Palacios (2010) on the 1980 and 2003 historical surveys, respectively. The number of sampling units covered by each vegetation type on each survey and characteristic (dominant) species are indicated.

\begin{tabular}{|c|c|c|c|}
\hline \multicolumn{4}{|c|}{ Number of sampling units } \\
\hline Vegetation type & 1980 & 2003 & Characteristic species \\
\hline \multirow[t]{5}{*}{ cardonal } & 7 & 7 & Cephalocereus columna-trajani \\
\hline & & & Bursera arida \\
\hline & & & Hechtia liebmannii \\
\hline & & & Agave kerchovei \\
\hline & & & Plumeria rubra \\
\hline \multirow[t]{5}{*}{ tetechera } & $16^{*}$ & 4 & Cephalocereus tetetzo \\
\hline & & & Varronia curassavica \\
\hline & & & Opuntia tomentosa \\
\hline & & & Lantana camara \\
\hline & & & Pseudosmodingium andrieuxii \\
\hline \multirow[t]{5}{*}{ shrubland } & 4 & 15 & Vachellia constricta \\
\hline & & & Agave marmorata \\
\hline & & & Parkinsonia praecox \\
\hline & & & Prosopis laevigata \\
\hline & & & Myrtillocactus geometrizans \\
\hline
\end{tabular}

* One of these patches was transformed to crop field. So it was removed from the RA.

1982). The altitude ranges from 1,280 to $2,720 \mathrm{~m}$ asl. (Zavala-Hurtado 1982). The average temperature is $28^{\circ} \mathrm{C}$ and the average annual rainfall is $380 \mathrm{~mm}$ (Zavala-Hurtado 1982). Soils are rocky and shallow, derived mainly from sedimentary and metamorphic rocks. The valley is mainly covered by tropical xerophytic scrub with a physiognomic predominance of columnar cacti (Rzedowski 1978, Valiente-Banuet et al. 1991).

Historical vegetation surveys. Through 1980, ZavalaHurtado (1982) carried out a characterization of the vegetation of the Zapotitlán valley from 30 sampling sites. The selection of the sites was preferential and tried to cover different physiognomic modalities of vegetation accessed from extensive routes throughout the valley. The location of each site was marked on a topographic chart and referenced in field notebooks, and the locations of roads, towns and outstanding geomorphological features in the vicinity of each site were identified. A $50 \times 5 \mathrm{~m}$ transect was chosen at each site and all the individuals of perennial plants present in each transect were registered and identified. The consideration of only perennial species allowed the sampling to be carried out throughout the year. In this survey, 85 perennial plant species were recorded at the sampling sites (Zavala-Hurtado 1982). Multivariate classification analyses (cluster analysis using Ward's method and multiple discriminant analysis) allowed the characterization of three main types of vegetation in the Zapotitlán valley (Table 1). Cardonal, characterized by the presence of the giant unbranched columnar cactus, Cephalocereus columna-trajani. Tetechera, dominated by the giant branched columnar cactus, Cephalocereus tetetzo. Shrubland, dominated by thorny trees and shrubs, legumes, agaves, and small cacti (Zavala-Hurtado 1982).

In 2003, 23 years later, Sandoval-Palacios (2010) returned to the original location of 28 of the original 30 sampling sites because two sites were inaccessible at that time. Furthermore, two of these 28 sites were eliminated from the study because they had been completely transformed and lacked vegetation cover. So, the second survey included only 26 of the original sites. In these stands, the same sampling procedures of the environmental and biological variables were repeated as in 1980 (Sandoval-Palacios 2010). A total of 104 perennial plant species was recorded in 2003 and the same three types of vegetation as described in 1980 were recognized by using the same multivariate techniques.

In this work, to verify the consistence of the three recognized types of local communities, we performed another multivariate classification analysis (cluster analysis, 


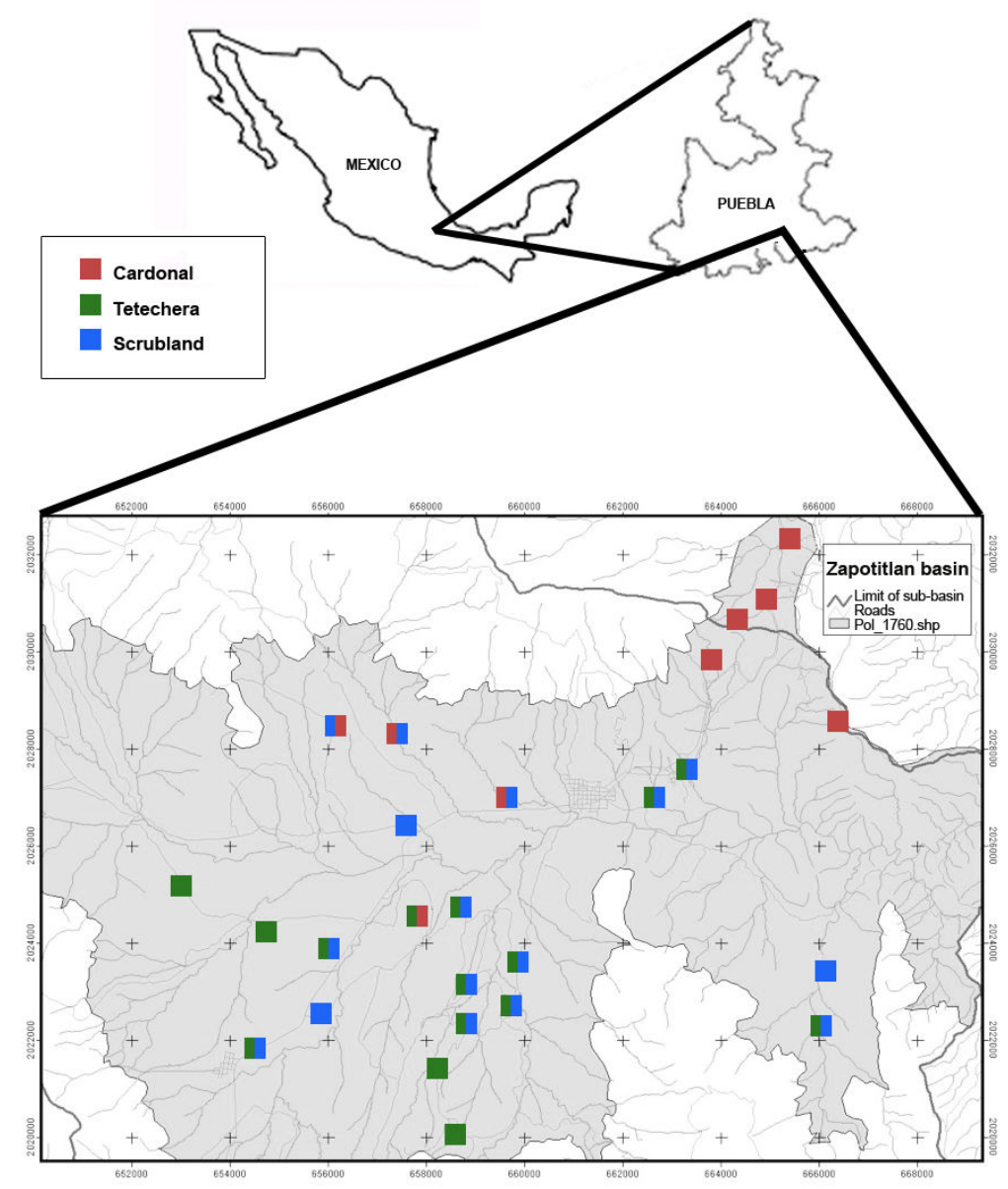

Figure 2. Distribution of 26 sampling sites in the semiarid Zapotitlán valley (color squares), where the studied metacommunity was defined (Zavala-Hurtado 1982, Sandoval-Palacios 2010). The color on the left side of each square represents the type of community registered in the 1980 survey and the color on the right side to that of 2003: red = cardonal; green $=$ tetechera; blue $=$ scrubland.

using Ward's method) on the joint incidence matrix of the two surveys (1980 and 2003). Additionally, we performed a principal component analysis (PCA) of the correlation matrix (Kovach 2013) on the same joint incidence matrix to visualize the magnitude of the compositional changes in the local communities after 23 years. Multivariate analyzes for this work were performed using the MVSP software (version 3.22, Kovach Computing Services, Pentraeth, Wales, UK).

Spatial variables. Zavala-Hurtado (1982) in the 1980 survey, at each sampling site and at the middle point of each transect, recorded the altitude ( $\mathrm{m}$ asl.) using an analog Thommen Classic altimeter, and the slope inclination $\left(^{\circ}\right)$ using a Brunton Pocket transit compass. These measurements were repeated in 2003 (Sandoval-Palacios $\underline{2010}$ ) to verify the location of the sampling sites. In 2003, the altitude ( $\mathrm{m}$ asl.) and the location of the sampling sites (UTM WGS84) were recorded using a Garmin 12CX GPS and the slope of terrain $\left(^{\circ}\right)$ using the same Brunton Pocket transit as that used in 1980. As a proxy for stand's isolation, related to dispersal limitation (Nekola \& White 1999, Moritz et al. 2013), we estimated the distance $(\mathrm{km})$ between stand from the longitudinal and latitudinal UTM coordinates for each site using BaseCamp 4.7.0 (Garmin 2018).

Environmental variables. During the two historical surveys, at $5 \mathrm{~m}$ from the longitudinal edges and in the center of each transect, soil depth was measured, and three soil samples were taken at a depth of $15 \mathrm{~cm}$. These samples were mixed to obtain a composite sample for each transect, in order to evaluate differences between sites. The variables texture, $\mathrm{pH}, \mathrm{CII}$, organic matter and the nutrients $\mathrm{Na}, \mathrm{K}, \mathrm{P}, \mathrm{Ca}$ and $\mathrm{Mg}$ were quantified for each sample in the Edaphology 
Laboratory of the National Institute of Research on Biotic Resources (currently Institute of Ecology, AC) for the 1980 survey and in the Soils Fertility Laboratory of the University of Chapingo for the 2003 survey. Standard extraction and quantification techniques were used as described in Sandoval-Palacios (2010).

Metacommunity structure analysis. There are several methods for ordering an incidence matrix so that the arrangement obtained preserves the similarities and differences in the ranges of species distribution and in the composition of species between sites (Leibold \& Mikkelson 2002). We used a method that evaluates the ordination of species and sites in gradients extracted by using a multivariate analysis of reciprocal averaging (RA), because it leads to a stable solution that does not depend on the initial arrangement of sites. Additionally, the ordination obtained by this method is not distorted by involution, at least in the first axis of variation, compared to other techniques such as PCA (Gauch et al. 1977). Furthermore, it allows recognition of joint variations in the structure of the metacommunity and environmental factors since ecological ordination seeks an understanding of gradient relationships between communities through the ordering of data along implicit environmental gradients (Whittaker 1967, Austin 1976).

The structure of the metacommunity was evaluated using presence-absence data of all the species recorded in the 26 patches sampled in 1980 and 2003. We used the metacom package V.1.5.1, from Dallas (2014), in R code V.3.6.1 ( $\mathrm{R}$ core team 2019). This software provides the coherence, turnover and boundary clumping functions for the analysis of the elements of the metacommunity structure within a framework proposed by Leibold \& Mikkelson (2002) and Presley et al. (2010). These functions are evaluated from the ordination of the species and sites in gradients extracted by means of a reciprocal averaging (RA) multivariate analysis (Gauch et al. 1977) on incidence matrices. This maximizes the proximity of species with similar distributions and the proximity of sites with compositions of similar species. The null model used to assess the significance of coherence and species' turnover was the " $\mathrm{r} 1$ ", which is the recommended one when species are distributed along environmental or spatial gradients, and because it is less sensitive to type I and type II errors (Presley et al. 2010). This model preserves the species richness of a site (row totals) and fills the species ranges (columns) based on their marginal probabilities. For each analysis, 1000 null matrices were simulated obtaining the ordination of species and samples on the first RA axis. For the boundary clumping analysis, metacom calculates the Morisita Index (Morisita 1962) on the presence-absence matrix, using a chi-squared test for significance. A significant value $>1$ indicates that the limits are clumped, and a significant value $<1$ indicates that the limits are not grouped. Thus, the idealized distribution patterns (nested, Clementsian, Gleasonian, evenly spaced, random, and checkerboard patterns, as well as the quasipatterns) within the metacommunity of the study were determined for both 1980 and 2003. We compared the metacommunity structures between the two years to assess possible temporal changes.

Relationship between the structure of the metacommunity and environmental and spatial variables. The EMS analysis allows one to describe the structure of the metacommunity in a domain delimited by an indirect gradient defined by the first RA axis. However, this analysis does not permit an identification of the factors that could be responsible for generating the observed patterns. To analyze the effect of each factor (environmental, spatial, environmental + spatial, and those not explained) in the metacommunity structure, we used a variance partition approach by applying partial canonical correspondence analysis (PCCA) (Borcard et al. 1992). This is a multivariate equivalent to partial linear regression (Borcard et al. 2011) and applies the varpart function of the vegan package V.6.1 for R V.3.6.1 ( $\mathrm{R}$ core team 2019). To assess the significance of particular variables within each explanatory matrix (environmental and spatial), we used canonical correspondence analysis (CCA) (Borcard et al. 2011). Before performing the PCCA and CCA analyzes, a multicollinearity test was applied to the soil variables to avoid increases in variance due to a possible correlation between the variables. For this test we used the pairs function in the car package v.3.0-3 for $\mathrm{R}$ v.3.6.1 ( $\underline{\mathrm{R} \text { core team } 2019}$ ).

\section{Results}

Temporal changes in local community types. The results of the classification (Figure 3A) and ordination analyses (Figure 3B) on the joint matrix of the two temporal surveys are consistent with the previous analyses made with the matrices for each separate survey date (Zavala-Hurtado 1982, Sandoval-Palacios 2010). There is a clear distinction between the cardonal communities and those of the tetechera and scrubland in that although they form different groups, some of the sites appear intermingled in the boundary between these community types in the ordination space. The characterization of these three types of community is based on the recurring presence of representative species characterized from their scores on the first two axes of the PCA (Figure 3B): cardonal (Cephalocereus columna-trajani, Mascagnia seleriana, Jatropha dioica, Agave kerchovei, Euphorbia cymbifera, Bursera arida, Hechtia liebmannii); tetechera (Cephalocereus tetetzo, Lantana camara, Varronia curassavica, Plumeria rubra, Opuntia tomentosa); and 

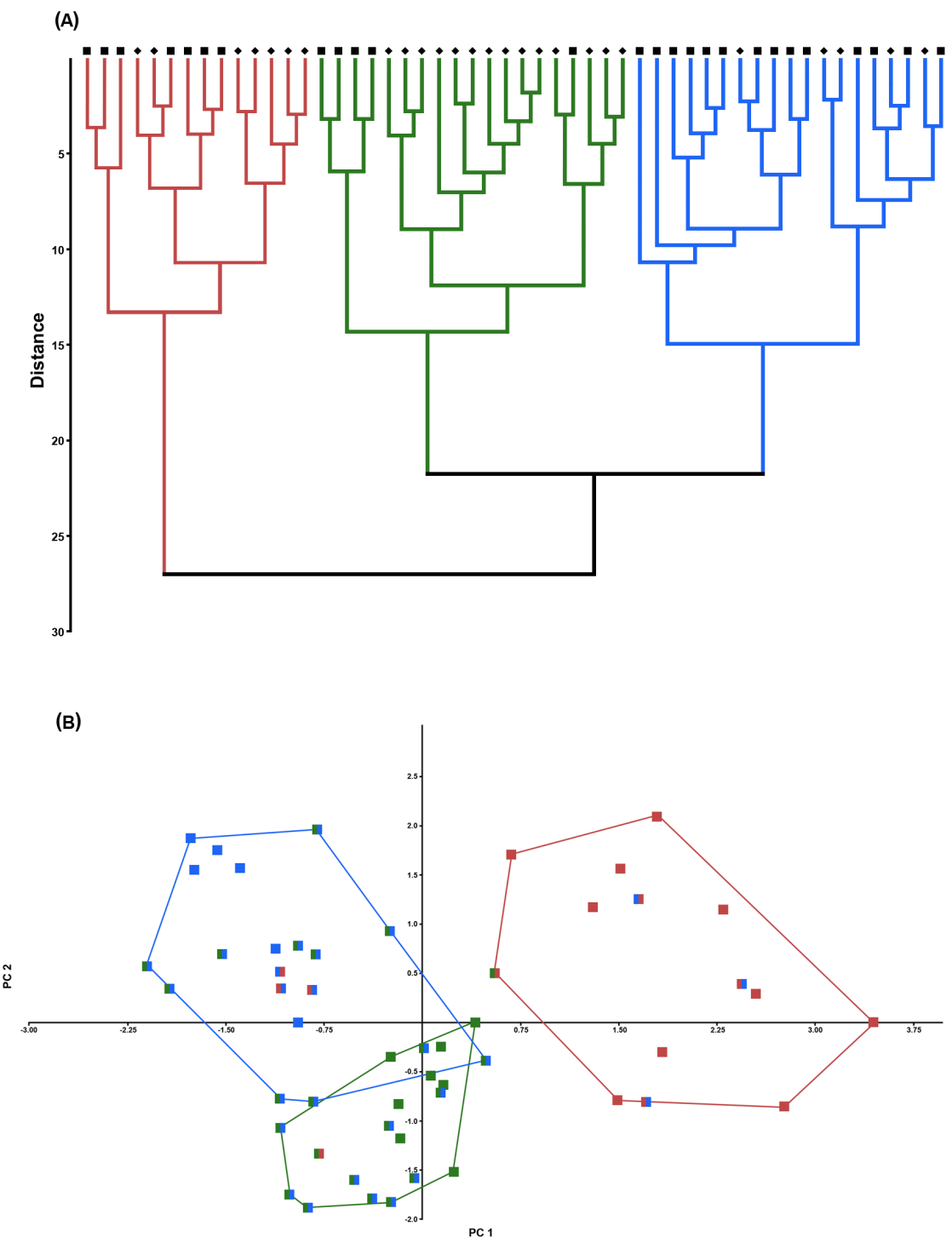

Figure 3. Dendrogram from a Ward's method Cluster analysis (A) and Principal Components Analysis (B) on a 1980-2003 joint incidence matrix (104 species in $26 \times 2$ stands) of a plant metacommunity in the semiarid Zapotitlán valley, Mexico. Symbols in the dendrogram are: diamonds $=1980$ survey; squares $=2003$ survey. Different colors indicate the previously assigned type of community ( $\underline{\text { Zavala-Hurtado } 1982}$,

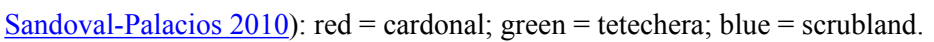

scrubland (Prosopis laevigata, Myrtillocactus geometrizans, Parkinsonia praecox, Gymnosperma glutinosum, Opuntia pilifera, Celtis pallida, Lemaireocereus hollianus, Dalea carthagenensis, Agave marmorata). It also can be seen that the cardonal sites, though were displaced within the territory of this type of community, maintaining their identity in the two temporal surveys. In contrast, most of the sites originally identified as tetechera were reclassified as scrubland, and those that remained identified as tetechera in 2003 were now placed on the border between these two types of community.
Metacommunity structure. When considering the two survey times in the light of an analysis of the three metacommunity structural elements, there were significantly fewer embedded absences than those anticipated by the null model; that is, there was positive coherence. The species' turnover was significantly greater than that expected from the null model; that is, there was no nested structure. Finally, the metacommunity showed significant clumping of species' ranges, the values of the Morisita Index being $>1$ and different from those expected from chance (Table 2). So, the metacommunity showed a Clementsian structure 
that had not changed after 23 years (Figure 4). Nevertheless, the individual elements did show some changes. While coherence and range boundary clumping showed decrement, turnover had increased 23 years after the first survey (Table 2).

Structuring mechanisms: environmental and spatial factors. Of the 12 soil variables initially considered as possible structuring factors of the metacommunity, those that were severely multicollinear (variance inflation factor $>10$ ) and those that showed a non-significant and low correlation with the first CCA axis were eliminated. This was done for both survey times, and the number of soil variables entered into the analysis was six in 1980 and four in 2003. None of the three spatial variables showed multicollinearity. The variation partition analysis used to assess the independent effect of spatial and environmental gradients on the spatial structure of the metacommunity for the 1980 survey indicated that the environmental effects, after removing the spatial effects, explained $15.1 \%$ of the total variation. The effects associated with space, without the environmental effects, accounted for $8.2 \%$ of the total variation. The variation shared by the effects of environmental and spatial variables was $0.07 \%$. The unexplained variation (the residuals) was $76.5 \%$, and this represented the un-assessed effects (of chance and noise) that do not depend on the environment, on the space, or on their joint effect (Figure 5A; Table 3). For the 2003 survey, the variation explained by spatial factors was $9.2 \%$, whereas the contribution of the environmental filters was $9.3 \%$. The variation explained by environmental and spatial effects was negative $(-1.8 \%)$, and such cases are regarded as zero values (Borcard et al. 2004). The variance not explained by any of the gradients evaluated (environmental and spatial) was $83.3 \%$ (Figure 5B; Table 3 ).
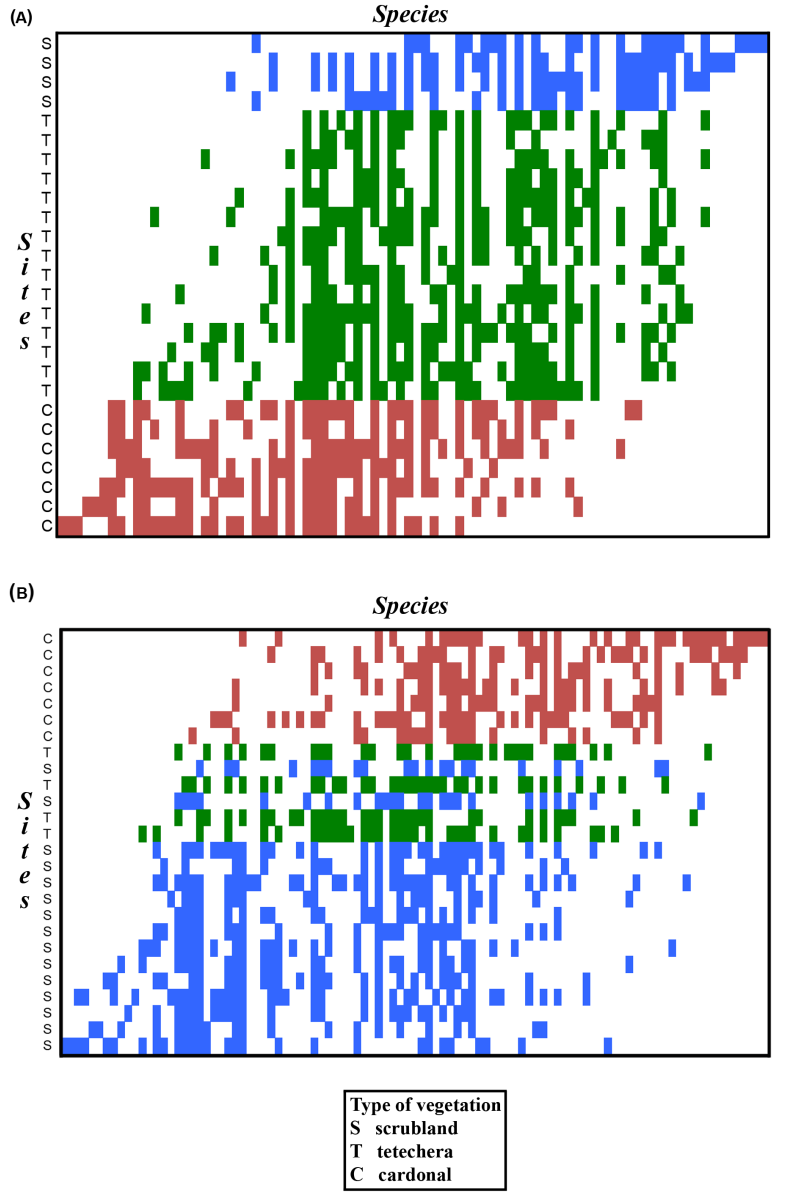

Figure 4. Reciprocal Averaging ordination of incidence matrices: (A) 84 species in 26 stands (1980), and (B) 104 species in 26 stands (2003) of a plant metacommunity in the semiarid Zapotitlán valley, Mexico. Colored squares represent incidence of species in each stand. Different colors indicate previously assigned type of community (Zavala-Hurtado 1982, Sandoval-Palacios 2010): red = cardonal; green $=$ tetechera; blue $=$ scrubland .

Table 2. Results of the analyses of coherence, species turnover and boundary clumping for the plant desert metacommunity of the Zapotitlán valley in two historical surveys (1980 and 2003). Metacommunity elements were extracted from the primary ordination axis (reciprocal averaging, RA). Mean and (SD) values were estimated from 1,000 generated null matrices, based on the r1 null model. EA = embedded absences, $\mathrm{SR}=$ species replacements, $\mathrm{MI}=$ Morisita Index. Significant results $(p<0.05)$ are in bold.

\begin{tabular}{|c|c|c|c|c|c|c|c|c|c|c|c|c|c|}
\hline & \multicolumn{5}{|c|}{ Coherence } & \multicolumn{5}{|c|}{ Spatial turnover } & \multicolumn{3}{|c|}{ Boundary clumping } \\
\hline & $\mathbf{E A}$ & Mean & $p$ & $\mathbf{z}$ & SD & SR & Mean & $p$ & $\mathbf{z}$ & SD & MI & $p$ & Best fit structure \\
\hline $\begin{array}{l}1980 \\
\text { Axis1 }\end{array}$ & 819 & 1258 & $<\mathbf{0 . 0 0 1}$ & 13.6 & 32.5 & 40738 & 20154 & $<0.001$ & -6.93 & 2970 & 1.54 & $<\mathbf{0 . 0 0 1}$ & Clementsian \\
\hline $\begin{array}{l}2003 \\
\text { Axis1 }\end{array}$ & 1119 & 1601 & $<0.001$ & 13.1 & 36.7 & 58771 & 34476 & $<0.001$ & -5.71 & 4251 & 1.48 & $<\mathbf{0 . 0 0 1}$ & Clementsian \\
\hline
\end{tabular}



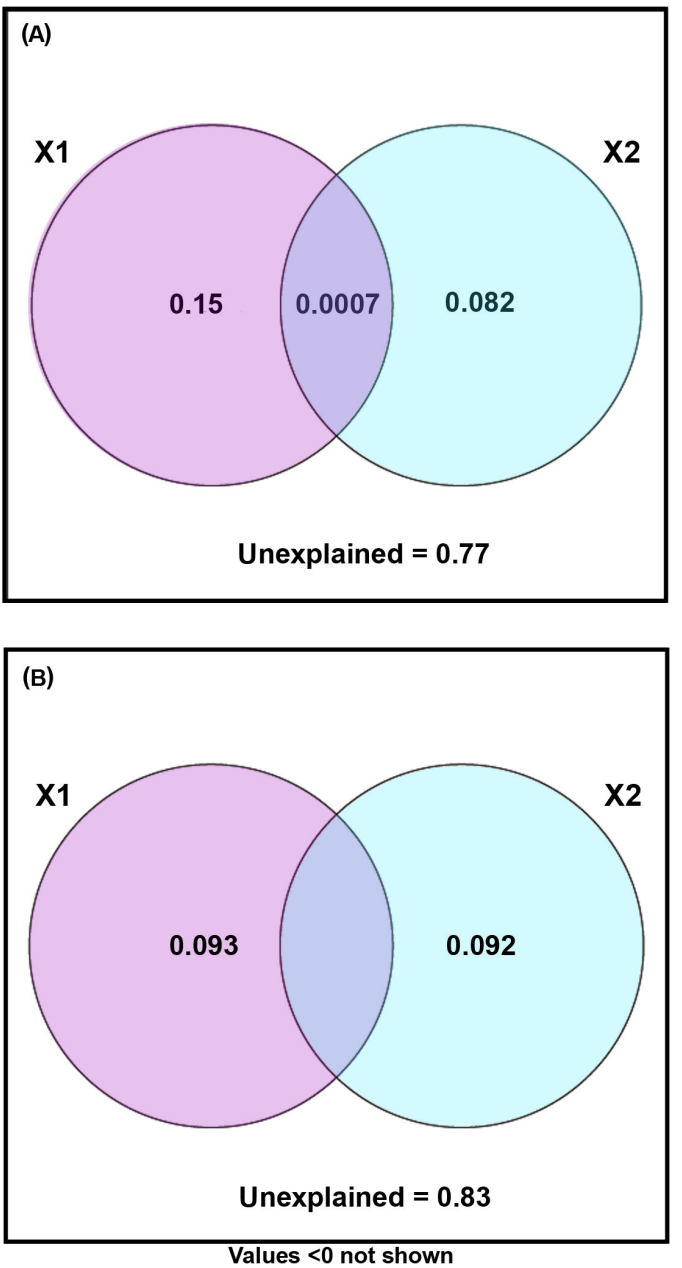

Figure 5. Venn diagrams showing variance partitioning of species distribution in the metacommunity in 1980 (A) and 2003 (B) surveys with environmental (soil) and spatial explanatory variables using partial CCA analyses. X1 = environmental (soil) matrix, $\mathrm{X} 2$ = spatial matrix. The overlapped area between the two circles is the variance explained jointly by the two matrices.

To identify the individual variables that influenced the results described above, we assessed the correspondence between the species incidence matrix and the environmental and spatial matrices in separate CCAs for each survey. In the 1980 survey, five environmental variables showed a significant correlation with the first CCA axis: $\mathrm{Na}, \mathrm{K}, \mathrm{Mg}, \mathrm{P}$ and organic matter (Table 4). In contrast, at the second survey (2003), only two environmental variables were significantly correlated with the first canonical component, $\mathrm{Ca}$ and $\mathrm{P}$ (Table 4).

In 1980, three spatial variables were significantly correlated with the first of the CCA axes: slope, latitude, and longitude. In 2003, only the spatial variables latitude and longitude showed significant correlation with the first canonical axis (Table 4).

\section{Discussion}

Temporal changes in local community types. After combining the samples from 1980 and 2003, we found a pattern consistent with previous analyses performed separately that clearly separated the three recognized types of local communities (shrubland, cardonal and tetechera) (Zavala-Hurtado 1982, Sandoval-Palacios 2010). Although the sites identified as cardonal remained as such over time (Sandoval-Palacios 2010), there were dramatic changes in the tetechera community, suggesting a scrubland encroachment into lands previously occupied by tetechera. This change could be driven by anthropogenic disturbances that involve the loss of species characteristic of the tetechera, particularly the giant columnar cactus Cephalocereus tetetzo, and thus would constitute a stage in a long-term successional process (Sandoval-Palacios 2010).

Metacommunity structure. The plant metacommunity of the Zapotitlán valley showed a Clementsian structure in the 1980 survey, which was maintained 23 years later, despite the documented changes in the composition and abundance of the species present in local communities. For this intertropical semi-arid region it is the first work on the dynamics of the structure of plant metacommunities and, as far as we know, also for Mexico, where studies on the dynamics of the structure of metacommunities have only been developed for bats (López-González et al. 2012) and amphibians (Ochoa-Ochoa \& Whittaker 2014). This Clementsian arrangement is consistent with the discrete segregation of the three previously defined types (Table 1) for the

Table 3. Correlation of the species distribution in the metacommunity with the environment (soil) and spatial variables using partial CCA analyses. Zero values are regarded as $R<0$. NT $=$ no testable. Significant results $(p<0.05)$ are in bold.

\begin{tabular}{llll}
\hline PCCA 1980 & \multicolumn{3}{l}{ PCCA 2003} \\
\hline Presence-absence matrix vs. & Adj. $R(p$ value $)$ & Presence-absence matrix vs. & Adj. $R(p$ value $)$ \\
Environment & $0.15(\mathbf{0 . 0 0 1})$ & Environment & $0.093(\mathbf{0 . 0 0 8})$ \\
Spatial & $0.08(\mathbf{0 . 0 0 1})$ & Spatial & $0.092(\mathbf{0 . 0 0 2})$ \\
Environment-Spatial & $0.0006(\mathrm{NT})$ & Environmental-Spatial & $0(\mathrm{NT})$ \\
\hline
\end{tabular}


Table 4. Canonical coefficients and the intraset correlation of environmental and spatial variables with the first two axes of canonical correspondence analysis (CCA). Significant results $(p<0.05)$ are in bold.

\begin{tabular}{lllc}
\hline \multicolumn{4}{c}{ CORRELATION COEFFICIENTS } \\
\hline $\mathbf{1 9 8 0}$ & Axis 1 & Axis 2 & $p$ \\
Environmental variables & & & \\
$\quad$ Phosphorous & 0.59 & 0.13 & $\mathbf{0 . 0 1 9}$ \\
Magnesium & 0.61 & 0.41 & $\mathbf{0 . 0 2 0}$ \\
Sodium & 0.87 & 0.37 & $\mathbf{0 . 0 0 6}$ \\
Potassium & 0.63 & -0.12 & $\mathbf{0 . 0 0 9}$ \\
CII & 0.10 & 0.48 & 0.82 \\
Organic matter & -0.11 & 0.62 & $\mathbf{0 . 0 0 1}$ \\
Spatial variables & & & \\
$\quad$ Altitude & -0.09 & 0.35 & 0.333 \\
Slope & -0.26 & -0.68 & $\mathbf{0 . 0 4 0}$ \\
Latitude & -0.65 & -0.26 & $\mathbf{0 . 0 0 2}$ \\
$\quad$ Longitude & -0.92 & 0.12 & $\mathbf{0 . 0 0 3}$ \\
2003 & & & \\
Environmental variables & & & \\
Phosphorous & 0.07 & -0.94 & $\mathbf{0 . 0 1 9}$ \\
Calcium & -0.96 & -0.18 & $\mathbf{0 . 0 0 4}$ \\
Magnesium & -0.15 & -0.22 & 0.525 \\
Organic material & -0.34 & 0.03 & 0.288 \\
Spatial variables & & & \\
Altitude & -0.15 & -0.93 & 0.062 \\
Slopes & 0.09 & 0.03 & 0.665 \\
Latitude & -0.57 & 0.57 & $\mathbf{0 . 0 0 2}$ \\
Longitude & -0.84 & 0.36 & $\mathbf{0 . 0 0 1}$ \\
\hline & & & \\
\hline
\end{tabular}

26 local communities in their ordination along the RA gradient with the sequential ordering of cardonal-tetecherashrubland sites (Figure 4). Although there was no temporary change in the Clementsian structure, the coherence and grouping of the species distribution limits showed a decrease, although not statistically significant (Table 2). However, this allows us to suggest that the decrease in these two elements of the metacommunity structure is possibly an ongoing trend towards homogenization. This can be seen in the RA ordination diagram in 2003 (Figure 4B), where two local communities determined as shrubland were interspersed among the tetechera communities and where the number of shrubland increased. However, caution should be exercised with these assumptions because we only have the data of two discrete points in time. In order to get a more complete idea of the dynamics of these patches, it is necessary to consider more points over time.

According to the theory of metacommunities (Leibold \& Mikkelson 2002, Presley 2010), the Clementsian structure of the metacommunity of the Zapotitlán valley implies that it has a coherent spatial distribution, with replacement of species between local communities and with grouping of the range limits of distribution of the species. That is, it is organized in different discrete types of communities and the constituent species respond similarly to the biotic and abiotic environmental factors of each local community (Clements 1916).

Other studies that have evaluated the dynamics of structure over time have also found temporal stability (Ellis et al. 2006, Azeria \& Kolasa 2008, Keith et al. 2011, Newton et al. 2012, Erös et al. 2014). However, only the work of Keith et al. (2011) and Newton et al. (2012) were related to plant communities (Southern England forest and Dorset calcareous grasslands, respectively). They also found a Clementsian structure that remained stable after 70 years, despite a loss in diversity recorded in that time interval. Although these are different ecosystems from the one we studied, these stability results are consistent with ours. Apparently, although there are temporary changes in the composition and abundance of species in local communities, both in plants (Keith et al. 2011) and in other groups of organisms (Ellis et al. 2006, Azeria \& Kolasa $\underline{2008}$, Erös et al. 2014), the different types of communities within the metacommunity are maintained. In the case of the Zapotitlán valley, the structure of the plant metacommunity did not show changes after 23 years, although there were dramatic changes in the composition and relative abundance in some of the local communities. Thus, the three types of communities (shrubland, tetechera and cardonal) that make up the meta-community persisted during the time covered by the study, although the number of tetechera communities decreased and the number of shrubland communities increased (Sandoval-Palacios 2010).

Structuring mechanisms: environmental and spatial factors. The variance partition of the effect of the environmental gradient (edaphic variables) and spatial (distance between patches), suggest that in 1980 the environmental filter had a greater effect than the spatial one as structuring mechanisms of the metacommunity (Figure 5A). This is in accordance with the Clementsian pattern for this year. For the 2003 survey, the environmental and spatial gradients explained the same percentage of variability (Figure 5B), while the Clementsian structure was maintained. This suggests that, in the plant metacommunity of the Zapotitlán valley, both factors would be important in the dynamics of species distribution. Our results are similar to those of Qian \& 
Shimono (2012), who found, for a metacommunity of Tibetan alpine meadows in China, that the distribution of species correlated with the joint effect of geographical and environmental distance, which explained almost the same percentages of variability (4.8 and $3.5 \%$, respectively). It has also been reported that in the Amazon rainforest both geographical distance and environmental factors contribute in almost equal proportion to the assembly of local communities (Tuomisto et al. 2003). In contrast to what we found in the studied semi-arid environment, Hassler et al. (2010), in a study on the savannah in northwestern Namibia, did not find a relationship with either geographical distance or with environmental gradients. This suggests that deterministic and stochastic factors are not exclusive or static, and that at different points in time and space one or the other may have greater influence (Chase \& Myers 2011). Additionally, they can act together to determine patterns of distribution of species at the level of metacommunities, as seen in the Zapotitlán valley.

Because it is very difficult to measure dispersal directly, one way to assess the effect of dispersal limitation on the metacommunity structure is through geographical distance between communities, which can be used as a proxy of connectivity between patches and can give an idea of the limits of regional dispersal (Nekola \& White 1999, Hassler et al. 2010, Moritz et al. 2013). That is, closer patches have a greater chance of exchanging species than farther patches (Wang et al. 2011, Siefert et al. 2012, Qian \& Shimono 2012, Moritz et al. 2013). Dispersal limitation has been recognized as a fundamental process in the dynamics of metacommunities (MacArthur \& Wilson 1967, Hubbell et al. 1999, Nathan \& Muller-Landau 2000, Jones et al. 2015). When considering the dynamics of semiarid metacommunities, Shreve (1929) and Shreve \& Hinckley (1937) suggested that observed changes in the structure of local Arizona communities were due only to species movement between patches. This would indicate a trend toward a more uniform representation of species throughout a study area. Thus, the spatial and temporal changes observed in the Zapotitlán valley, given by increased species' frequency/incidence in certain local communities, might be due to the arrival of plant species from other nearby patches or from the seed bank. However, environmental filters must be overcome because the patches within the Zapotitlán valley are immersed in a relatively unfavorable matrix. So the species must be able to reach new patches and fall into suitable sites for their establishment (Silvertown \& Wilson 1994). In Zapotitlán, as well as in other arid environments, it has been found that these favorable sites often tend to occur under the canopies of shrubs that generate a microenvironment, where the radiation, temperature and humidity conditions are tempered, compared to open spaces (Valiente-Banuet et al.
1991). It has also been reported that under these shrubs there is greater accumulation of nutrients in the soil (Franco \& Nobel 1989, Valiente-Banuet \& Ezcurra 1991, PerroniVentura et al. 2010). Although it was not the objective of this work, we suggest that the conceptual paradigm of metacommunities (Holyoak et al. 2005) that could be adjusted to the semi-arid metacommunity of the Zapotitlán valley would be the 'species sorting' one. This, because the metacommunity has an apparently stable Clementsian structure in the analyzed time window. In addition, environmental and spatial filtering showed a small but significant effect on the structure of the metacommunity.

Finally, we found no evidence to support our hypothesis that the influence of changes in the composition and abundance of species at the level of local communities could affect the meta-community structure, tending towards homogenization. The Clementsian structure with discrete local communities was maintained over time. Our results also did not support the hypothesis about the importance of structuring mechanisms. From the recognized Clementsian distribution, we expected that the soil characteristics would have more influence than the distance between the patches; however, both gradients explained almost the same proportion of variability. This shows us that the Zapotitlán valley has a Clementsian structure that did not change despite changes in species diversity in local communities after 23 years. This suggests that the Clementsian structure is robust to local changes. Besides, it seems that there are multiple mechanisms and processes that influence the assembly and structure of metacommunities, since the gradients we consider in this work only explain $23 \%$ (1980) and $18 \%$ (2003) of the total variability. Many other biotic and abiotic factors must be acting in the dynamics of the communities. Because of this, multiple environmental gradients need to be considered, including temporary variations in climatic and spatial factors, as well as longerterm monitoring at the study sites.

\section{Acknowledgements}

The Basic Science Program (Grant 000000000179296) of the Mexican Council of Science and Technology (CONACYT) supported this research. This work is part of MJ's PhD project for the Doctorado en Ciencias Biológicas y de la Salud of the Universidad Autónoma Metropolitana and was supported by a doctoral scholarship from CONACYT. We are deeply grateful to Pedro Miranda and Juan Manuel Gallardo for their assistance in the field. Ismael Calzada, Francisco González Medrano, Fernando Chiang and Juan Manuel Gallardo aided with the identification of plant specimens. Silvio Olivieri and Enrique Martínez contributed in the planning and development of the first survey in 1980. 


\section{Literature cited}

Abella SR, Guida RJ, Roberts CL, Norman CM, Holland JS. 2019. Persistence and turnover in desert plant communities during a $37-\mathrm{yr}$ period of land use and climate change. Ecological Monographs 89: 1-20. DOI: https://doi.org/10.1002/ecm.1390

Aguiar MR, Sala OE. 1994. Competition, facilitation, seed distribution and the origin of patches in a Patagonian steppe. Oikos 70: 26-34. DOI: https://doi.org/10.2307/ $\underline{3545695}$

Austin MP. 1976. On non-linear species response models in ordination. Vegetatio 33: 33-41. DOI: https://doi.org/ $\underline{10.1007 / B F 00055297}$

Azeria ET, Kolasa J. 2008. Nestedness, niche metrics and temporal dynamics of a metacommunity in a dynamic natural model system. Oikos 117: 1006-1019. DOI: https://doi.org/10.1111/j.0030-1299.2008.16529.x

Borcard D, Legendre P, Drapeau P. 1992. Partialling out the spatial component of ecological variation. Ecology 73: 1045-1055. DOI: https://doi.org/10.2307/1940179

Borcard D, Legendre P, Avois-Jacquet C, Tuomisto H. 2004. Dissecting the spatial structure of ecological data at multiple scales. Ecology 85: 1826-1832. DOI: https:// doi.org/10.1890/03-3111

Borcard D, Gillet F, Legendre P. 2011. Numerical Ecology with $R$. New York: Springer. DOI: https://doi.org/ $\underline{10.1007 / 978-1-4419-7976-6}$

Chase JM, Bengtsson J. 2010. Increasing spatio-temporal scales: metacommunity ecology. In: Verhoef HA, Morin PJ, eds. Community Ecology. Processes, models, and applications. New York: Oxford University Press, pp. 57-68. ISBN-13: 9780199228973

Chase JM, Myers JA. 2011. Disentangling the importance of ecological niches from stochastic processes across scales. Philosophical Transactions of the Royal Society 366: 2351-2363. DOI: https://doi.org/10.1098/rstb.2011. $\underline{0063}$

Clements FE. 1916. Plant Succession: Analysis of the development of vegetation. Washington: Carnegie Institution of Washington, DOI: https://doi.org/10.5962/ bhl.title. 56234

Dallas T. 2014. metacom: an R package for the analysis of metacommunity structure. Ecography 37: 402-405. DOI: https://doi.org/10.1111/j.1600-0587.2013.00695.x

Datry T, Bonada N, Heino J. 2015. Towards understanding the organization of metacommunities in highly dynamic ecological systems. Oikos 125: 149-159. DOI: https:// doi.org/10.1111/oik.02922

Denelle P, Violle C, Munoz F. 2019. Distinguishing the signatures of local environmental filtering and regional trait range limits in the study of trait-environment relationships. Oikos 128: 960-971. DOI: https://doi.org/ 10.1111/oik.05851

Devlaeminck R, Bossuyt B, Hermy M. 2005. Inflow of seed through the forest edge: evidence from seed bank and vegetation patterns. Plant Ecology 176: 1-17. DOI: https://doi.org/10.1007/s11258-004-0008-2

Diamond JM. 1975. Assembly of species communities. In: Cody ML, Diamond JM, eds. Ecology and evolution of communities. Massachusetts: Harvard University Press, pp. 342-444. ISBN 9780674224445

Ellis AM, Lounibos LP, Holyoak M. 2006. Evaluating the long-term metacommunity dynamics of tree hole mosquitoes. Ecology 87: 2582-2590. DOI: https:// doi.org/ 10.1890/0012-9658(2006)87[2582:ETLMDO]2.0.CO;2

Erös T, Sály P, Takás P, Higgins CL, Bíró P, Schmera D. 2014. Quantifying temporal variability in the metacommunity structure of stream fishes: the influence of non-native species and environmental drivers. Hydrobiologia 722: 31-43. DOI: https://doi.org/10.1007/ s10750-013-1673-8

Franco AC, Nobel PS. 1989. Effect of nurse plants on the microhabitat and growth of cacti. Journal of Ecology 77: 870-886. DOI: https://doi.org/10.2307/2260991

Garmin 2018. Garmin Ltd. BaseCamp owner's manual. Kansas, USA.

Gauch HG, Whittaker RH, Wentworth TR. 1977. A comparative study of reciprocal averaging and other ordination techniques. Journal of Ecology 65: 157-174. DOI: https://doi.org/10.2307/2259071

Gleason HA. 1926. The individualistic concept of the plant association. Bulletin of the Torrey Botanical Club 53: 7-26. DOI: https://doi.org/10.2307/2479933

Hassler SK, Kreyling J, Beierkuhnlein C, Eisold J, Samimi C, Wagenseil H, Jentsch A. 2010. Vegetation pattern divergence between dry and wet season in a semiarid savanna - spatio-temporal dynamics of plant diversity in northwest Namibia. Journal of Arid Environments 74:1516-1524. DOI: https://doi.org/10.1016/j.jaridenv. 2010.05.021

Holyoak M, Leibold MA, Mouquet N, Holt RD, Hoopes MF. 2005. Metacommunities. A framework for largescale community ecology. In: Holyoak M, Leibold MA, Holt RD, eds. Metacommunities. Spatial dynamics and ecological communities. Chicago: Chicago University Press, pp.1-31. ISBN: 9780226350646

Hubbell SP, Foster RB, O'Brien ST, Harms KE, Condit R, Wechsler B, Wright SJ, Loo de Lao S. 1999. Light-gap disturbances, recruitment limitation, and tree diversity in a Neotropical forest. Science 283: 554-557. DOI: https:// doi.org/10.1126/science.283.5401.554

Hubbell SP. 2005. Neutral theory in community ecology and the hypothesis of functional equivalence. Functional 
Ecology 19: 166-172. DOI: https://doi.org/10.1111/ j.0269-8463.2005.00965.x

Hutchinson MAS. 2008. Interactions between habitat fragmentation and invasion: factors driving exotic plant invasion in native forest remnants West Coast New Zealand. $\mathrm{PhD}$. Thesis. University of Canterbury.

Jones NT, Germain RM, Grainger TN, Hall AM, Baldwin L, Gilbert B. 2015. Dispersal mode mediates the effect of patch size and patch connectivity on metacommunity diversity. Journal of Ecology 103: 935-944. DOI: https:// doi.org/10.1111/1365-2745.12405

Keith SA, Newton AC, Morecroft MD, Golicher DJ, Bullock JM. 2011. Plant metacommunity structure remains unchanged during biodiversity loss in English woodlands. Oikos 120: 302-310. DOI: https://doi.org/ $\underline{10.1111 / \mathrm{j} .1600-0706.2010 .18775 . \mathrm{x}}$

Kovach WL. 2013. MVSP - A MultiVariate Statistical Package for Windows, v.3.22. Pentraeth, Wales, UK. Kovach Computing Services.

Leibold MA, Mikkelson GM. 2002. Coherence, species turnover, and boundary clumping: elements of metacommunity structure. Oikos 97: 237-250. DOI: https:// doi.org/10.1034/j.1600-0706.2002.970210.x

Leibold MA, Holyoak M, Mouquet M, Amarasekare P, Chase JM, Hoopes MF, Holt RD, Shurin JB, Law R, Tilman D, Loreau M, Gonzalez A. 2004. The metacommunity concept: a framework for multi-scale community ecology. Ecology Letters 7: 601-613. DOI: https://doi.org/10.1111/j.1461-0248.2004.00608.x

Leibold MA, McPeek MA. 2006. Coexistence of the niche and neutral perspectives in community ecology. Ecology 87: 1399-1410. DOI: https://doi.org/10.1890/0012-9658 (2006)87[1399:COTNAN]2.0.CO;2

Logue JB, Mouquet $\mathrm{N}$, Peter $\mathrm{H}$, Hillebrand $\mathrm{H}$, Metacommunity Working Group. 2011. Empirical approaches to metacommunities: a review and comparison with theory. Trends in Ecology and Evolution 26: 482-491. DOI: https://doi.org/10.1016/ j.tree.2011.04.009

López-González C, Presley SJ, Lozano A, Stevens RD, Higgins CL. 2012. Metacommunity analysis of mexican bats: environmentally mediated structure in an area of high geographic and environmental complexity. Journal of Biogeography 39: 177-192. DOI: https://doi.org/ 10.1111/j.1365-2699.2011.02590.x

MacArthur RH, Wilson EO. 1967. The theory of island biogeography. Princeton: Princeton University Press. ISBN: 9780691088365

Meynard CN, Lavergne S, Boulangeat I, Garraud L, Van Es J, Mouquet N, Thuiller W. 2013. Disentangling the drivers of metacommunity structure across spatial scales. Journal of Biogeography 40: 1560-1571. DOI: https:// doi.org/10.1111/jbi.12116
Miller TJ, Quintana-Ascencio PF, Maliakal-Witt S, Menges ES. 2012. Metacommunity dynamics over 16 years in a pyrogenic shrubland. Conservation Biology 26: 357-366. DOI: https://doi.org/10.1111/j.1523-1739.2011.01807.x

Mouquet N, Loreau M. 2003. Community patterns in source-sink metacommunities. The American Naturalist 162: 544-556. DOI: https://doi.org/10.1086/378857.

Morisita M. 1962. Id-index, a measure of dispersion of individuals. Researches on Population Ecology 4: 1-7. DOI: http://dx.doi.org/10.1007/BF02533903

Moritz C, Meynard CN, Devictor V, Guizien K, Labrune J, Guarini M, Mouquet N. 2013. Disentangling the role of connectivity, environmental filtering, and spatial structure on metacommunity dynamics. Oikos 122: 1401-1410. DOI: https://doi.org/10.1111/j.1600-0706. 2013.00377.x

Nathan R, Muller-Landau HC. 2000. Spatial patterns of seed dispersal, their determinants and consequences for recruitment. Trends in Ecology and Evolution 15: 278-285. DOI: https://doi.org/10.1016/S0169-5347(00) $\underline{01874-7}$

Nekola JC, White PS. 1999. The distance decay of similarity in biogeography and ecology. Journal of Biogeography 26: 867-878. DOI: https://doi.org/10.1046/ j.1365-2699.1999.00305.x

Newton AC, Walls RM, Golicher D, Keith SA, Diaz A, Bullock JM. 2012. Structure, composition and dynamics of calcareous grassland metacommunity over a 70 -year interval. Journal of Ecology 100: 196-209. DOI: https:// doi.org/10.1111/j.1365-2745.2011.01923.x

Ochoa-Ochoa LM, Whittaker RJ. 2014. Spatial and temporal variation in amphibian metacommunity structure in Chiapas, Mexico. Journal of Tropical Ecology 30: 537-549. DOI: https://doi.org/10.1017/ $\underline{\mathrm{S} 0266467414000388}$

Ozinga WA, Bekker RM, Schaminée JHJ, Van Groenendael JM. 2004. Dispersal potential in plant communities depends on environmental conditions. Journal of Ecology 92: 767-777. DOI: https://doi.org/10.1111/ j.0022-0477.2004.00916.xs

Patterson BD, Atmar W. 1986. Nested subset and the structure of insular mammalian faunas and archipelagos. Biological Journal of the Linnean Society 28: 65-82. DOI: https://doi.org/10.1111/j.1095-8312.1986.tb01749.x

Perroni-Ventura Y, Montaña C, García-Oliva F. 2010. Carbon-nitrogen interactions in fertility island soil from a tropical semi-arid ecosystem. Functional Ecology 24: 233-242. DOI: https://doi.org/10.1111/j.1365-2435.2009. 01610.x

Presley SL, Higgins CL, Willig MR. 2010. A comprehensive framework for the evaluation of metacommunity structure. Oikos 119: 980-917. DOI: https://doi.org/10.1111/j.1600-0706.2010.18544.x 
Pueyo Y, Kefi S, Alados CL, Rietkerk M. 2008. Dispersal strategies and spatial organization of vegetation in arid ecosystems. Oikos 117: 1522-1532. DOI: https://doi.org/ $\underline{10.1111 / \mathrm{j} .0030-1299.2008 .16735 . \mathrm{x}}$

Puth LM, Post DM. 2005. Studying invasion: have we missed the boat? Ecology Letters 8: 715-721. DOI: https://doi.org/10.1111/j.1461-0248.2005.00774.x

Qian H, Shimono A. 2012. Effects of geographic distance and climatic dissimilarity on species turnover in alpine meadow communities across a broad spatial extent on the Tibetan Plateau. Plant Ecology 213: 1357-1364. DOI: https://doi.org/10.1007/s11258-012-0095-4

R Core Team 2019. R: A language end environment for statistical computing. $\mathrm{R}$ Foundation for Statistical Computing. Vienna, Austria. http://www.R-project.org/.

Rzedowki J. 1978. Vegetación de México. Mexico City: Limusa. ISBN: 968-18-0002-8

Sandoval-Palacios E. 2010. Patrones de variación espaciotemporal del matorral xerófilo en la subcuenca de Zapotitlán, Puebla. MSc. Thesis, Universidad Autónoma Metropolitana.

Shreve F. 1929. Changes in desert vegetation. Ecology 10: 364-373. DOI: https://doi.org/10.2307/1931144

Shreve F, Hinckley AL. 1937. Thirty years of change in desert vegetation. Ecology 18: 463-478. DOI: https:// doi.org/10.2307/1930573

Siefert A, Ravenscroft C, Weiser MD, Swenson NG. 2012. Functional beta-diversity patterns reveal deterministic community assembly processes in eastern North American trees. Global Ecology and Biogeography 22: 682-691. DOI: https://doi.org/10.1111/geb.12030

Silvertown J, Wilson JB. 1994. Community structure in a desert perennial community. Ecology 75: 409-417. DOI: https://doi.org/10.2307/1939544.

Simberloff D. 1983. Competition theory, hypothesis testing, and other community ecological buzzwords. American Naturalist 122: 626-635. DOI: https://doi.org/ $\underline{10.1086 / 284163}$.

Stewart J, Parsons AJ, Wainwright J, Okin GS, Bestelmeyer BT, Fredrickson EL, Schlesinger WH. 2014. Modeling emergent patterns of dynamic desert ecosystems.
Ecological Monographs 84: 373-410. DOI: https:// doi.org/10.1890/12-1253.1

Tilman D. 1982. Resource competition and community structure. Monographs in Population Biology 17. Princeton: Princeton University Press, 296. ISBN: 9780691083025

Tuomisto H, Ruokolainen K, Yli-Halla M. 2003. Dispersal, Environment, and Floristic Variation of Western Amazonian Forests. Science 299: 241-244. DOI: https:// doi.org/10.1126/science.1078037

Valiente-Banuet A, Ezcurra E. 1991. Shade as a cause of the association between the cactus Neobuxbaumia tetetzo and the nurse plant Mimosa luisana in the Tehuacan Valley, Mexico. Journal of Ecology 79: 961-971. DOI: https://doi.org/10.2307/2261091

Valiente-Banuet A, Vite F, Zavala-Hurtado JA. 1991. Interaction between the cactus Neobuxbaumia tetetzo and the nurse shrub Mimosa luisana. Journal of Vegetation Science 2: 14-11. DOI: https://doi.org/10.2307/3235892

Venable DL, Flores-Martínez A, Muller-Landau HC, Barron-Gafford G, Becerra JX. 2008. Seed dispersal of desert annuals. Ecology 89: 2218-2227. DOI: https:// doi.org/10.1890/07-0386.1

Wang X, Wiegand T, Wolf A, Howe R, Davies SJ, Hao Z. 2011. Spatial patterns of tree species richness in two temperate forests. Journal Ecology 99: 1382-1393. DOI: https://doi.org/10.1111/j.1365-2745.2011.01857.x

Whittaker RH. 1967. Gradient analysis of vegetation. Biological Reviews 42: 207-264. DOI: https://doi.org/ $\underline{\text { 10.1111/j.1469-185X.1967.tb01419.x }}$

Wilson DS. 1992. Complex interactions in metacommunities, with implications for biodiversity and higher levels of selection. Ecology 73: 1984-2000. DOI: https://doi.org/10.2307/1941449

Zavala-Hurtado JA. 1982. Estudios ecológicos en el valle semiárido de Zapotitlán, Puebla. I. Clasificación numérica de la vegetación basada en atributos binarios de presencia y ausencia de las especies. Biotica 7: 99-119.

\footnotetext{
Associate editor: Enrique Jurado

Author contributions: JM, JAZH and ESP designed the study. JM, ESP, JAZH, GHC and BRA designed and carried out the field work. MJ, CM, JAZH and EV built-up the analysis design. All authors collaborated in the manuscript preparation.
} 